\title{
Erratum to: Non-Branching Moderate Moralism
}

\section{Scott Clifton}

Published online: 12 December 2013

(C) Springer Science+Business Media Dordrecht 2013

\section{Erratum to: Philosophia \\ DOI 10.1007/s11406-013-9488-4}

In this paper Alessandro Giovannelli's name was misspelled. The mistake was entirely my error and I regret any confusion or inconvenience resulting from it.

Additionally, the city in which the College of Charleston is located reads Seattle, WA. The correct city should be Charleston, SC.

The online version of the original article can be found at http://dx.doi.org/10.1007/s11406-013-9488-4.

S. Clifton $(\bowtie)$

Department of Philosophy, College of Charleston, Charleston, SC, USA

e-mail: cliftonss@cofc.edu 